This is the pre-peer reviewed version of the following article:

Vázquez, J. J., Piqueras, S., \& Panadero, S. (2020). Mothers living homeless in Madrid (Spain): Characteristics, vulnerabilities and relationships with their children. Child \& Family Social Work, 25(4), 904-914,

which has been published in final form at:

https://doi.org/10.1111/cfs. 12775

This article may be used for non-commercial purposes in accordance with Wiley Terms and Conditions for Use of Self-Archived Versions. 
Author's Pre-print of the article:

Vázquez, J. J., Piqueras, S., \& Panadero, S. (2020). Mothers living homeless in Madrid (Spain): Characteristics, vulnerabilities and relationships with their children. Child \& Family Social Work, 25(4), 904-914. DOI: doi.org/10.1111/cfs.12775

Copyright: $\mathbb{C}$ John Wiley \& Sons Ltd.

\title{
MOTHERS LIVING HOMELESS IN MADRID (SPAIN): CHARACTERISTICS, VULNERABILITIES AND RELATIONSHIPS WITH THEIR CHILDREN.
}

\author{
José Juan Vázquez ${ }^{1}$, Susana Piqueras ${ }^{1}$, and Sonia Panadero ${ }^{2}$
}

1. Social Psychology Department. Alcala University, 28801, Alcala de Henares. Madrid, Spain.

2. Clinical Psychology Department, School of Psychology, Complutense University of Madrid, 28223, Madrid, Spain.

Corresponding author: José Juan Vázquez, Departmento de Psicología Social, Universidad de Alcalá, C/San Cirilo, s/n. 28801 Alcalá de Henares, Madrid, España. Email: jj.vazquez@uah.es

Funding statement: This work was supported by the "Agencia Estatal de Investigación" of the "Ministerio de Economía, Industria y Competitividad" of Spain under Grant FEM201675317-R.

Conflicts of interest: None of the authors have any conflict of interest. 


\begin{abstract}
People in a homeless situation are one of the most obvious embodiments of the phenomenon of social exclusion, and women living homeless are a particularly vulnerable group. The article examines some of the differences between women who were mothers and those who had no children in a sample of women living homeless in Madrid (Spain) $(n=138)$. The information was collected using a structured interview. The results show that the women in a homeless situation who were mothers presented extremely difficult life experiences, and were a particularly vulnerable subgroup. None of the women in a homeless situation who were mothers lived with their children. The women who were mothers suffered from more chronic homelessness, slept the night in the street more frequently, and were in poorer health. Furthermore, throughout their life the women living homeless who were mothers had experienced more traumatic situations from early ages, with higher levels of psychoactive substance abuse and more problems with the legal system, which could have had a highly negative effect on their relationship and lives with their children. The different circumstances and needs of mothers in a homeless situation require the implementation of prevention and/or treatment approaches aimed at this specific subgroup.
\end{abstract}

Keywords: Homelessness; Women; Mother; Children; Vulnerability. 


\section{Introduction}

The Goal 1 of the Sustainable Development Goals (SDGs) aim to end poverty in all its forms everywhere, while leaving no one behind. In developed societies, people in a homeless situation are one of the most obvious embodiments of the phenomenon of poverty and social exclusion (Vázquez, Panadero, Martín, \& Díaz-Pescador, 2015). People living homeless not only live in extreme poverty, but also suffer from high levels of family and social disengagement, and have great difficulty in achieving social/employment reintegration, and significant health problems (Vázquez, Panadero, \& Zúñiga, 2017a, 2017b, 2018). Among people living homeless, women in a homeless situation are a particularly vulnerable group (Chambers, Chiu, Scott, Tolomiczenko, Redelmeier, Levinson, \& Hwang, 2014; Nyamathi, Leake \& Gelberg, 2000; Roll, Toro, \& Ortola, 1999; Vázquez \& Panadero, 2019; Zugazaga, 2004), with characteristics, necessities and life experiences that are different from those of their male peers (Vázquez et al., 2017b), and they are exposed to many highly intense negative circumstances from early ages (Panadero, Martín, \& Vázquez, 2018). Since women in a homeless situation account for a relatively small percentage of the group of people living homeless in Spain (around 16\%), there has been very little research with a gender perspective that has focused specifically on this group (Muñoz, Vázquez, \& Vázquez, 2004; Vázquez, Panadero, \& Pascual, in press; Vázquez et al., 2015).

Vázquez et al. $(2015,2017 \mathrm{a}, 2017 \mathrm{~b}, 2018)$ report that most people living homeless in Madrid (Spain) are men (84\%), of Spanish nationality (72\%), with a mean age of 47.5 years. More than half of the people living homeless in Madrid were single (53\%), and $41 \%$ were separated or divorced. According to Vázquez et al. (in press), women and men living homeless in Madrid did not differ significantly in terms of their main socio-demographic characteristics (age, nationality or marital status), although the women spent the night in shelters more often and slept less in the street often. The people living homeless in Madrid were chronically homeless to a significant extent regardless of gender, having been homeless for more than six years on average (Panadero et al., 2015). However, the phenomenon of the "revolving door to homelessness" seems to affect women to a greater extent in Madrid (Vázquez et al., in press). There are no gender differences among homeless people in Madrid for the use of heroin and cocaine. However, cannabis was consumed by a larger percentage of men among people living homeless in Madrid, while sedatives were consumed by women to a much greater extent, and more than half of them consumed these substances on a regular basis (Guillén, Marín-Martín, Panadero, \& Vázquez, in press). Homeless women in Madrid have a higher level of education than homeless men, nevertheless homeless women face more difficulties in both gaining access to the labour market and keeping their job (Vázquez et al., in press).

Women living homeless have to cope with multiple intersecting vulnerabilities: extreme poverty, a lack of social networks, physical and mental health problems, experiencing multiple and serious stressful life events at an early age, the consumption of psychoactive substances, prostitution, difficulties in accessing the labour market, etc. (Belcher, Greene, McAlpine, \& Ball, 2001; Guillén, et al., in press; Hatch, \& Dohrenwend, 2007; Herman, Susser, Struening, \& Link, 1997); Panadero et al., 2018; Vázquez et al., in press, 2017b). Unfortunately, the way in which a person experiences a disadvantage is inevitably determined by the other disadvantages they suffer from. As such, intersecting vulnerabilities tend to create hardships which are far greater than the sum of each factor, meaning that each factor amplifies the effect of the others, leading to greater hardship (Corus, Saatcioglu, Kaufman-Scarborough, Blocker, Upadhyaya, \& Appau, 2016). Motherhood can be another significant factor for added vulnerability in this context. 
Various studies have found that many women in a homeless situation have had children, although a large percentage of these women did not live with their children (Barrow \& Laborde, 2008; Burt, Aron, \& Lee, 2001; Cowal, Shinn, Weitzman, Stojanovic, \& Labay, 2002). The circumstances linked to motherhood and relationships with children can play an especially important role among women in a homeless situation. According to Zabkiewicz, Patterson and Wright (2014), the duration of homelessness may increase as a result of family fragmentation and separation from children, which may be a risk factor for traumas, suffering from psychological problems and the loss of guardianship of underage children.

Most of the children who were not living with their mothers in a homeless situation were living with relatives or in foster care (Burt et al., 2001; New York City Commission on Homelessness, 1992, p. B-5; Zlotnick, Tam, \& Bradley, 2007). Various circumstances have been reported as increasing the likelihood of women in a homeless situation being separated from their children, including psychoactive substance abuse, mental health problems, suffering from violence, anti-social behaviour, institutionalisation (e.g. hospitalisation on psychiatric grounds, imprisonment) and the mistreatment or neglect of the underage children (Belcher et al., 2001; Chambers et al., 2014; Cowal et al., 2002; Murrell et al., 2000; Zabkiewicz et al., 2014; Zlotnick, Kronstadt, \& Klee, 1998). Other issues which have also been identified as accounting for the high rates of separation from their underage children among women living homeless are related to the fact that many shelters do not allow underage children or families with children to stay there (Rossi, 1994), and that many mothers prefer their children to stay with relatives or in foster care for their safety and well-being, thereby avoiding the need for the children to stay in shelters for the homeless (Cowal et al., 2002; Shinn \& Weitzman, 1996). Women sometimes go to great lengths to distance themselves from their children in order not to present an image that could be detrimental (Cowal et al., 2002), particularly if they engage in criminal activities, prostitution, substance abuse, begging, etc. Glick (1996) points out that the separation of mothers in a homeless situation from their underage children is often a voluntary process, as by doing so the mothers seek to preserve their children's well-being, with the idea that it will be a temporary arrangement until they can find a secure home where they can be with them. Regrettably, Cowal et al. (2002) point out that these children rarely live with their mothers again.

The mothers in a homeless situation who did not live with their children tended to be older, and had been homeless for a longer period of time (Zlotnick et al., 2007). Various studies have shown that these mothers who did not live with their children had suffered from histories of childhood trauma to a greater extent. This included being thrown out of the family home or running away and physical or sexual abuse. In adulthood, these women were more likely to suffer from intimate partner violence, incarceration and had greater difficulties in gaining access to housing (Pavao, Alvarez, Baumrind, Induni, \& Kimerling, 2007; Zlotnick, Robertson, \& Lahiff, 1999; Zlotnick, Tam, \& Robertson, 2004; Zlotnick et al., 2007). Furthermore, many of the mothers who did not live with their children presented problems related to substance abuse and physical and mental health (Bassuk, Buckner, Perloff, \& Bassuk, 1988; Grant, Gracy, Goldsmith, Shapiro, \& Redlener, 2013; Hanrahan et al. 2005; Weinreb, Buckner, Williams, \& Nicholson, 2006).

Although it is relatively common in various cultural contexts for mothers in a homeless situation to be accompanied by their underage children in shelters for the homeless (Anderson, Stuttaford, \& Vostanis, 2006; Anthony, Vincent, \& Shin, 2018; Chambers et al., 2014; Zugazaga, 2004), and even on the street (Vázquez, Berrios, Bonilla, \& Suarez, 2019), in Madrid women with children are not observed on the street, or in shelters for people in a homeless situation. In Spain, where the family plays a crucial role in the social safety net 
providing against becoming homeless (Leonori et al., 2000), the protection of women and underage children from homelessness is particularly intense. Women in a homeless situation generally have relatives (Barrow \& Laborde, 2008; Cowal et al., 2002; Vazquez \& Panadero, 2019), although in most cases they do not have any significant contact with them (Tucker et al., 2009). Nevertheless, in many cases the relatives take care of these women's underage children (Barrow \& Laborde, 2008; Cowal et al., 2002) even when they do not have good relations with the mother.

In Madrid, the "Network of care centres for people living homeless" has only two accommodation facilities and one drop-in centre specifically for women living homeless (Ayuntamiento de Madrid, 2019), which means that women living homeless usually need to share shelters and care facilities which are mostly used by men (Guillén et al., in press). Given the relatively small percentage of women (16\%) among the people living homeless in Madrid (Vázquez et al., in press), accommodation and care facilities are mainly designed to meet men's needs, and are considered uncomfortable and unsafe by female users. The "Network of care centres for people living homeless" lacks facilities aimed at addressing the needs of families and/or mothers with children, although mothers responsible for children can sometimes access resources which are not associated with the network: these include hostels and low-rental homes, supervised accommodation, care centres for women victims of gender violence, shelters for asylum seekers, etc. Unfortunately, staying in this type of accommodation is usually subject to a time limit (Baptista, Benjaminsen, Pleace, \& BuschGeertsema, 2017).

Although various studies have highlighted that motherhood may be a particularly important issue among women living homeless (e.g. Anderson et al., 2006; Baptista et al., 2017; Barrow \& Laborde, 2008; Belcher et al., 2001; Chambers et al., 2014; Cowal et al., 2002; Vázquez et al., in press), the lack of research focusing on motherhood among women living homeless in Spain has rendered this situation invisible, and has severely restricted the specific analysis of the distinctive characteristics and needs of women who are mothers living homeless. This study examines the differences between women living homeless who were mothers and those who did not have children in Madrid (Spain). It focuses on different variables that enable an analysis of whether women who are mothers living homeless have different circumstances and needs, which require different approaches to prevention and/or treatment for this specific subgroup (Haskett, Loehman, \& Burkhart, 2016; Roll, et al., 1999; Zugazaga, 2004).

\section{Participants}

\section{Methodology}

The research was conducted in Madrid (Spain), based on the data provided by a sample of homeless women $(n=138)$. The criteria for inclusion in the sample were being a woman, and meeting the criteria for belonging to one of the first three operational categories in the "European Typology on Homelessness and Housing Exclusion" (ETHOS): 1) People living rough, 2) People in emergency accommodation, and 3) People in accommodation for the homeless. All the participants were adults, and had spent the night before the interview in a shelter or in a supervised accommodation for the homeless, in the street or in other places not initially designed for sleeping (abandoned buildings, basements, etc.). The main characteristics of the sample are shown in Table 1. 
Table 1. Characteristics of women living homeless interviewed in Madrid.

\begin{tabular}{lc}
\hline & $\begin{array}{c}\text { Women (n=138) } \\
\text { Mean / percentage }\end{array}$ \\
\hline Age & 45.52 years (SD=11.38) \\
\hline Nationality & $69.6 \%$ \\
Spanish & $30.4 \%$ \\
Foreign & \\
\hline Marital status & $54.4 \%$ \\
Single & $3.8 \%$ \\
Married & $29.1 \%$ \\
Legally separated or divorced & $10.1 \%$ \\
Separated de facto without legal procedures & $1.9 \%$ \\
Widowed & $0.6 \%$ \\
$\quad$ Other & \\
\hline Level of education & $9.4 \%$ \\
No education & $13.0 \%$ \\
Incomplete primary education & $32.6 \%$ \\
Primary education (up to 14 years old) & $27.5 \%$ \\
Secondary (up to 18 years old) & $17.4 \%$ \\
Higher university studies & $11.7 \%$ \\
\hline In the past month s/he has slept... & $81.9 \%$ \\
In the street & \\
In a shelter or supervised accommodation & 35.33 years (SD=14.96) \\
\hline Age when they become homeless & 75.26 months (SD=90.54) \\
\hline Time spent homeless &
\end{tabular}

As shown in Table 1, the mean age of the women interviewed was 45 years, and they had become homeless for the first time at an average age of 35 years. More than two thirds of the interviewees were of Spanish nationality, $22.4 \%$ had not completed primary school education and around half were single. Although $40 \%$ had been married at some point in their lives, very few were still married at the time the interview took place. The women interviewed had been living homeless for an average of more than six years, and $12 \%$ spent the night in the street or other places not initially designed for sleeping (abandoned buildings, basements, etc.).

\section{Procedures}

The women interviewed were recruited in shelters and drop-in centres for people living homeless, and in the street and in public spaces. All the facilities in the "Network of care centres for people living homeless" in Madrid which worked with women were contacted to gain access to the participants. The shelters and drop-in centres provided places that ensured the interviewees' comfort and privacy when the interviews were conducted. Occasionally, if the women wished, an appointment was made to meet and interview them somewhere else (in a cafeteria, park, mall, etc.). For women living in the street, outreach teams provided the location and facilitated contact with the interviewees. After making contact, the interviewers introduced themselves, asked for their cooperation and made sure that they met the criteria for inclusion in the sample. The interviews with women in street scenarios were conducted in cafeterias, fast food restaurants, parks, malls, etc. Places that provided the interviewees with comfort and privacy were sought. Due to the relatively small number of homeless women who spent the night in shelters, in supervised accommodation, in 
the street or in public spaces, all the women who were contacted who met the criteria for inclusion in the sample were asked to participate in the study.

In view of the results obtained in previous studies (Muñoz et al., 2004; Panadero, Guillén, \& Vázquez, 2015), we assumed that a relatively high number of interviewees would have a low or very low level of education, and that the number of women living homeless in Madrid of foreign origin - with potential difficulties with understanding the language - would be relatively high. As a result, a structured interview was used to gather information, which enabled us to circumvent the possible problems arising from the interviewees' difficulties with reading and/or understanding. The structured interview used was a version with a gender perspective of an instrument used in previous studies for people living homeless in Madrid (Vázquez et al., 2015, 2017a, 2017b, 2018), which was adapted to the fact that the interviewees were women. After the objectives of the research and the processing that the data would receive were explained to the participants, they were asked for their informed consent, and assured that their anonymity would be respected at all times. The interviews lasted between 45 and 80 minutes.

The database was developed and processed using the SPSS statistical analysis and data management system. When making comparisons, the $\chi 2$ "Chi-squared" statistic was used for nominal variables, and the "Student-t test for independent samples" was used for continuous variables.

\section{Results}

Of the 138 women living homeless interviewed in Madrid, 60.9\% (84) had been mothers, while $39.1 \%$ (54) reported that they had no children (non-mothers). The interviewees who had been mothers had a mean of 2.18 children $(\mathrm{SD}=1.300)$, and their first child had been born when the mother's mean age was 21.8 years old $(\mathrm{SD}=5.300)$. There are no statistically significant differences between the interviewees of Spanish and foreign nationality as regards the percentage of women who were mothers $(63 \%$ of Spanish women versus $58 \%$ of foreigners), nor for the average number of children per woman: this was 1.3 children $(\mathrm{SD}=1.312)$ for the Spanish women and 1.4 children $(\mathrm{SD}=1.703)$ for the foreigners. Some sociodemographic characteristics of the women in homeless situation (mothers and non-mothers) are shown in Table 2. 
Table 2. Sociodemographic characteristics and place of overnight stay for mothers and nonmothers women living homeless in Madrid.

\begin{tabular}{|c|c|c|c|}
\hline & $\begin{array}{c}\text { Mothers } \\
(\mathrm{n}=84)\end{array}$ & $\begin{array}{c}\text { Non-mothers } \\
(n=54)\end{array}$ & $t / \chi^{2}$ \\
\hline Age (M years, SD) & $46.74(10.476)$ & $43.63(12.528)$ & 1.514 \\
\hline Marital status & & & $18.023 * * *$ \\
\hline Single & $45.2 \%(38)$ & $81.5 \%(44)$ & \\
\hline Married & $8.3 \%(7)$ & $3.7 \%(2)$ & \\
\hline Legally separated or divorced & $27.4 \%(23)$ & $9.3 \%(5)$ & \\
\hline Separated de facto without legal procedures & $11.9 \%(10)$ & $3.7 \%(2)$ & \\
\hline Widow & $7.1 \%(6)$ & $1.9 \%(1)$ & \\
\hline Level of education & & & $7.364 * *$ \\
\hline $\begin{array}{l}\text { No education, did not complete primary education, } \\
\text { and primary education }\end{array}$ & $64.3 \%(54)$ & $40.7 \%(22)$ & \\
\hline $\begin{array}{l}\text { Secondary and higher education (university and } \\
\text { non-university) }\end{array}$ & $35.7 \%(30)$ & $59.3 \%(32)$ & \\
\hline Nationality & & & 2.171 \\
\hline Spanish & $67.9 \%(57)$ & $61.1 \%(33)$ & \\
\hline Foreign & $29.8 \%(25)$ & $31.5 \%(17)$ & \\
\hline Both & $2.4 \%(2)$ & $7.4 \%(4)$ & \\
\hline Has relatives & $94.0 \%(79)$ & $77.8 \%(42)$ & $8.055 * *$ \\
\hline Frequency of contact with her relatives & & & $12.199 * *$ \\
\hline Never & $46.8 \%(37)$ & $78.6 \%(33)$ & \\
\hline Less than once a month & $15.2 \%(12)$ & $7.1 \%(3)$ & \\
\hline Monthly & $10.1 \%(8)$ & $7.1 \%(3)$ & \\
\hline Weekly & $19.0(25)$ & $4.8 \%(2)$ & \\
\hline Almost every day & $9.8 \%(7)$ & $2.4 \%(1)$ & \\
\hline $\begin{array}{l}\text { Degree of satisfaction with her relationship with } \\
\text { her family }\end{array}$ & & & .408 \\
\hline Not at all & $31.6 \%(25)$ & $42.9 \%(18)$ & \\
\hline Not much & $16.5 \%(13)$ & $21.4 \%(9)$ & \\
\hline Quite a lot & $20.3 \%(16)$ & $14.3 \%(6)$ & \\
\hline A lot & $31.6 \%(25)$ & $21.4 \%(9)$ & \\
\hline \multicolumn{4}{|l|}{$\begin{array}{l}\text { In the month before the interview took place, she } \\
\text { slept in... }\end{array}$} \\
\hline The street & $16.9 \%(14)$ & $3.7 \%(2)$ & $5.496^{*}$ \\
\hline In an unsuitable place & $8.4 \%(7)$ & $6.6 \%(3)$ & .401 \\
\hline In a shelter & $77.4 \%(65)$ & $87.0 \%(47)$ & 2.004 \\
\hline
\end{tabular}

As can be seen from Table 2, there are no statistically significant differences between mothers and non-mothers living homeless in terms of their mean age, nationality or staying overnight in shelters or places not suitable for sleeping. However, more of the mothers were separated (either legally or de facto), had a lower level of education (mostly lacking education or completed primary education) and had spent the night in the street in the month before the interview. Almost all the mothers reported having relatives, with whom they had more regular contact than the non-mothers, although they did not report a higher level of satisfaction with their relationship with them.

The mothers were found to have been homeless for longer (taking all episodes of homelessness into account) (92.90 months; $\mathrm{SD}=99.816)$ than the non-mothers (46.82 months; $\mathrm{SD}=64.505)(\mathrm{t}=3.172 ; \mathrm{p}=.002)$, although no statistically significant differences were observed for the number of times they had become homeless. 
Table 3. Circumstances experienced before the age of 18 by mothers and non-mothers living homeless in Madrid.

\begin{tabular}{lccc}
\hline Circumstances experienced before the age of 18 & $\begin{array}{c}\text { Mothers } \\
(\mathbf{n}=\mathbf{8 4})\end{array}$ & $\begin{array}{c}\text { Non-mothers } \\
(\mathbf{n = 5 4 )}\end{array}$ & $\chi^{\mathbf{2}}$ \\
\hline Thrown out of home & $25.3 \%(21)$ & $9.4 \%(5)$ & $5.267^{*}$ \\
Suffered from abuse by someone in her family & $33.7 \%(28)$ & $19.2 \%(10)$ & $3.325^{*}$ \\
Suffered from sexual abuse & $36.1 \%(30)$ & $20.8 \%(11)$ & $3.638^{*}$ \\
\hline
\end{tabular}

As shown in Table 3, during their childhood and adolescence more of the mothers had been thrown out of the family home, or experienced sexual abuse or other abuse by family members.

During the mothers' childhood and adolescence, $14.3 \%$ (12) had been abandoned at a mean age of 8.8 years old, $(\mathrm{SD}=5.323), 41.7 \%$ (35) had suffered abuse from a mean age of 9.1 years old $(\mathrm{SD}=4.674)$ and $33.3 \%(28)$ had been sexually abused for the first time at an average age of 10.4 years old $(\mathrm{SD}=4.289)$. Furthermore, $25.0 \%(21)$ had been thrown out of family home at a mean age of 13.1 years old $(\mathrm{SD}=3,687)$ and $36.9 \%(31)$ had run away from the place where they lived at a mean age of 13.4 years old $(\mathrm{SD}=3.313)$. Likewise, $10.7 \%(9)$ were expelled from school at a mean age of 12.7 years old $(\mathrm{SD}=1.936)$, and $25.0 \%(21)$ dropped out of school at a mean age of 14.1 years old $(\mathrm{SD}=1.826)$.

Table 4. Consumption of psychoactive substances among mothers and non-mothers living homeless in Madrid.

\begin{tabular}{lccc}
\hline Consumption of psychoactive substances & $\begin{array}{c}\text { Mothers } \\
(\mathbf{n}=\mathbf{8 4})\end{array}$ & $\begin{array}{c}\text { Non-mothers } \\
(\mathbf{n}=\mathbf{5 4})\end{array}$ & $\chi^{\mathbf{2}}$ \\
\hline Drunk too much at some point in her life & $42.2 \%(35)$ & $26.4 \%(14)$ & $3.483^{*}$ \\
Abused drugs at some point in her life & $45.8 \%(38)$ & $24.5 \%(13)$ & $6.235^{* *}$ \\
\hline At some point during her life, she... & & & \\
$\quad$ Has used cocaine & $48.8 \%(41)$ & $29.6 \%(16)$ & $4.988^{*}$ \\
$\quad$ Has used heroin & $35.7 \%(30)$ & $11.1 \%(6)$ & $10.319^{* * *}$ \\
$\quad$ Has used methadone & $26.2 \%(22)$ & $11.1 \%(6)$ & $4.621^{*}$ \\
$\quad$ Has used cannabis & $46.4 \%(39)$ & $29.6 \%(16)$ & $3.870^{*}$ \\
$\quad$ Has used sedatives & $66.7 \%(56)$ & $46.3 \%(25)$ & $5.626^{*}$ \\
\hline Has received treatment for drug abuse & $31.0 \%(26)$ & $14.8 \%(8)$ & $4.610^{*}$ \\
Has received treatment for alcohol abuse & $16.7 \%(14)$ & $5.6 \%(3)$ & $3.757^{*}$ \\
\hline Has used some type of illegal drug in the 12 months & $26.2 \%(22)$ & $13.0 \%(7)$ & $3.465^{*}$ \\
prior to the interview & & & \\
\hline
\end{tabular}

As shown in Table 4, a larger percentage of the mothers reported having consumed alcohol and drugs to excess at some point during their lives, as well as during the 12 months prior to the interview. A larger percentage of these women reported having consumed all the psychoactive substances that were mentioned in the research, with large differences for heroin consumption. A higher percentage of the mothers interviewed said that they had received treatment for consumption of alcohol or drugs.

The mothers reported that they had used drugs excessively from a mean age of 21.6 years $(\mathrm{SD}=8.218)$, and had done so before becoming homeless in $65.8 \%$ of cases. Likewise, the mothers who said that they had consumed alcohol to excess reported that they began to do so at an average age of 28.3 years old $(\mathrm{SD}=11.465)$, and before becoming homeless in $60.0 \%$ of the cases. 
Table 5. Criminal activities, problems with the legal system and violence experienced by mothers and non-mothers living homeless in Madrid.

\begin{tabular}{lccc}
\hline & $\begin{array}{c}\text { Mothers } \\
(\mathbf{n = 8 4 )}\end{array}$ & $\begin{array}{c}\text { Non-mothers } \\
(\mathbf{n = 5 4 )}\end{array}$ & $\chi^{\mathbf{2}}$ \\
\hline $\begin{array}{l}\text { Criminal activities and problems with the legal } \\
\text { system }\end{array}$ & & & \\
$\quad$ She has engaged in criminal activities & $34.5 \%(29)$ & $17.3 \%(9)$ & $4.728^{*}$ \\
$\quad$ She has been arrested or detained for a crime & $47.0 \%(39)$ & $26.4 \%(14)$ & $5.756^{*}$ \\
$\quad$ She has been convicted at some time & $32.5 \%(27)$ & $15.1 \%(18)$ & $5.145^{*}$ \\
$\quad$ She has been in prison & $32.5 \%(27)$ & $11.3 \%(6)$ & $7.918^{* *}$ \\
\hline Violence suffered as adults (over 18 years old) & & & \\
$\quad$ Intimate partner violence & $71.1 \%(59)$ & $35.8 \%(19)$ & $16.418^{* * *}$ \\
$\quad$ Physical violence & $60.2 \%(50)$ & $42.3 \%(22)$ & $4.131^{*}$ \\
\hline
\end{tabular}

As shown in Table 5, a larger percentage of the mothers interviewed reported having engaged in criminal activities, having been arrested or detained for committing a crime, having been convicted and having been imprisoned. A larger percentage of these same mothers interviewed had suffered from intimate partner violence and physical violence during their adult life.

The mothers who had been arrested after committing a crime were arrested for the first time at a mean age of 29.3 years old $(\mathrm{SD}=12.021)$, and in $52.6 \%$ of the cases had been arrested for the first time prior to becoming homeless; and those who had been convicted and imprisoned had been convicted for the first time at a mean age of 29.9 years old $(\mathrm{SD}=12.313)$. This was before becoming homeless in $48.1 \%$ of cases. Among the mothers interviewed, $58.3 \%$ (49) suffered from physical violence in their adult lives at a mean age of 26.9 years old $(\mathrm{SD}=8.070$ ), and in $56.0 \%$ of cases this occurred for the first time before they became homeless. $32.1 \%(27)$ were sexually assaulted at a mean age of 28.2 years old $(\mathrm{SD}=9.673)$, with $60.7 \%$ being sexually assaulted for the first time prior to becoming homeless.

Table 6. State of health of mothers and non-mothers living homeless in Madrid.

\begin{tabular}{lccc}
\hline & $\begin{array}{c}\text { Mothers } \\
(\mathbf{n = 8 4})\end{array}$ & $\begin{array}{c}\text { Non-mothers } \\
(\mathbf{n = 5 4 )}\end{array}$ & $\chi^{\mathbf{2}}$ \\
\hline Has a diagnosed serious or chronic illness. & $61.4 \%(51)$ & $41.5 \%(22)$ & $6.183^{* *}$ \\
\hline Has a disability $_{\quad}$ Is certified as disabled $^{1}$ & $43.2 \%(35)$ & $26.9 \%(38)$ & $3.610^{*}$ \\
& $71.4 \%(25)$ & $66.7 \%(10)$ & .113 \\
\hline Suffers from HIV/AIDS & $20.5 \%(17)$ & $7.5 \%(4)$ & $4.145^{*}$ \\
\hline At some point during her life... & & & \\
$\quad$ Has become pregnant without wanting to & $60.5 \%(49)$ & $32.0 \%(16)$ & $10.041^{* * *}$ \\
$\quad$ Has had an abortion & $43.4 \%(36)$ & $25.0 \%(13)$ & $4.668^{*}$ \\
$\quad$ Has suffered from a miscarriage & $30.1 \%(25)$ & $15.4 \%(8)$ & $3.759^{*}$ \\
\hline Has attempted suicide $^{1}$ Percentages of interviewees who reported having a disability & & &
\end{tabular}

As shown in Table 6, the mothers interviewed were in poorer health, had more serious or chronic diseases (including HIV/AIDS) and higher percentages of disability. During their lives, a large majority of the mothers had experienced unwanted pregnancies, as well as more interrupted pregnancies, including both miscarriages and abortions. Finally, over half of the mothers interviewed reported having attempted suicide. 
The mothers who reported having suffered from a serious illness, injury or accident first did so at a mean age of 29.8 years old $(\mathrm{SD}=16.308)$, and did so before becoming homeless in $64.7 \%$ of cases. The mothers interviewed who had experienced unwanted pregnancies had become pregnant against their wishes for the first time at a mean age of 23.6 years old ( $\mathrm{SD}=7.095)$, and prior to becoming homeless in $77.1 \%$ of cases; those who had undergone an abortion did so for the first time at a mean age of 25.4 years old $(\mathrm{SD}=7.796)$, prior to becoming homeless in $82.9 \%$ of cases; and those who suffered from a miscarriage did so for the first time at a mean age of 27.8 years old $(\mathrm{SD}=8.375)$, before becoming homeless in $72.0 \%$ of cases. The mothers interviewed who reported having attempted suicide at some time had done so for the first time at a mean age of 29.1 years old $(\mathrm{SD}=12.626)$, and in $58.3 \%$ of cases had done so prior to becoming homeless.

$5.9 \%$ (5) of the mothers interviewed had a child who had died when the mother's mean age was 28.8 years old $(\mathrm{SD}=19.665)$. This was before becoming homeless in $80 \%$ of cases, and $53.6 \%$ (45) had been separated from their children at a mean age of 31.2 years old $(\mathrm{SD}=8.885$ ), prior to becoming homeless in $51.1 \%$ of cases. $45.2 \%$ (38) of the mothers interviewed had underage children at the time of the interview, although none of them lived with them. 63.2\% (24) had lost guardianship (the authority granted to a person or institution to care for an individual) of at least one of their children. The reasons the women attributed to their loss of guardianship of their children were financial problems $(27.6 \%, 11)$; consumption of alcohol or drugs $(24.1 \%, 9)$; a lack of social and/or institutional support $(10.3 \%, 4)$; migratory processes $(6.9 \%, 3)$; physical and mental health problems $(3.1 \%, 1)$; and intimate partner violence inflicted by the father of their children $(3.1 \%, 1)$.

All the mothers knew where their underage children were: $30.4 \%$ (12) were living with their maternal grandparents; $21.4 \%$ (8) were living with the children's father; $17.9 \%(6)$ were living with other relatives; $10.7 \%$ (4) were in an institution; $10.7 \%$ (4) had been adopted; 7.1\% (3) had children in foster families, and 1.8\% (1) said they were "in another situation." As for the contact between the mothers interviewed and their underage children, $39.1 \%$ (15) reported having no contact, $10.4 \%$ (4) said they had sporadic contact (once a year), 10.4\% (4) were in infrequent contact (less than once a month), 29.9\% (11) were in frequent contact (approximately once a week) and $10.4 \%$ (4) were in very frequent contact (every day, or almost every day).

\section{Discussion}

According to the scientific literature, women in a homeless situation are an extremely vulnerable group (Chambers et al., 2014; Nyamathi et al., 2000, Roll et al., 1999; Vázquez \& Panadero, 2019; Vázquez et al., in press; Zugazaga, 2004), and the results of this study show that women living homeless who had children have had to cope with particularly negative life circumstances. In Madrid, women living homeless who were mothers had to deal with intersecting vulnerabilities to a greater extent than those who were not mothers: they had lower levels of education, less contact with family members and a poorer relationship with their relatives, stayed overnight stays in the street to a greater extent, suffered from more stressful life events during childhood and adulthood, consumption more alcohol and/or drugs, were involved in more criminal activities and had more problems with the legal system, suffered from higher levels of intimate partner violence and more physical violence, were in poorer health, had attempted suicide on more occasions, etc. Under these circumstances, motherhood could be an added vulnerability factor for these women living homeless, which would place mothers living homeless in situations of serious social difficulty when influenced by other serious vulnerabilities. 
In Madrid, the women in a homeless situation who were mothers $(60 \%$, with a mean of 2.2 children per woman) had experienced more stressful life situations from an early age, and presented particularly severe personal deterioration and more chronic homelessness, with a mean period of homelessness of around 8 years. These women had their first child at a relatively early age (a mean of 22 years old) compared to the mean age at which women in Spain have their first child, which is 30.9 years old (Spanish National Institute of Statistics, 2018). Becoming a mother at a relatively early age, which could be related to the difficult previous life history of the interviewees, could in turn have had negative impacts on various aspects of their life (Vázquez \& Panadero, 2016).

Although it is relatively common in many cultural contexts for shelters for the homeless to accommodate mothers with their underage children (Anderson et al., 2006; Chambers et al., 2014; Cowal et al., 2002; Grant et al., 2013; Weinreb et al., 2006; Zugazaga, 2004), no homeless woman in Madrid was living with her children, despite the fact that $45 \%$ reported having underage children, and $37 \%$ had retained guardianship of them. The specific services providing assistance for people in a homeless situation in Madrid are not aimed at families with children, and as such it is common for the underage children of women living homeless to live with their maternal grandparents, their father or other close relatives.

Although none of the women interviewed in Madrid lived with their underage children, $40.3 \%$ were in frequent contact with them. However, $39 \%$ of the mothers interviewed reported not having any contact with their underage children, mainly because they were in an institution or they had been given up for adoption. In the Spanish cultural context, the family environment tends to provide high levels of protection for women at risk of becoming homeless and their children (Leonori et al., 2000). This special protection is also provided by government bodies, which are particularly sensitive to women and minors, as they are considered especially vulnerable groups.

In this Spanish cultural context, with strong social protection from families (Leonori et al., 2000), the family relationship breaks down in cases in which the situation is particularly problematic, which is why it is common for the relationship between the women living homeless and their families to have deteriorated markedly. Although the vast majority of the mothers interviewed said they had relatives with whom they were in relatively regular contact, they also reported not having a higher level of satisfaction with their relationship with them than the women in a homeless situation who had not had children. These family difficulties could also begin at a very early age, as the fact that more of these women have experienced stressful life events during childhood appears to suggest. In line with the observations made in various cultural contexts (Barrow, \& Laborde, 2008; Zlotnick et al., 2004), the women in a homeless situation in Madrid who had been mothers said they had experienced a particularly difficult childhood and adolescence, had suffered from a very large number of serious stressful life events, including physical and sexual violence (experienced at a mean age of under 10 years old), as well as serious problems in their family environment: neglect, being thrown out of home, running away, domestic violence, etc. experienced at a mean age of around 13 years old. These mothers were also found to have high rates of academic failure before 14 years old (dropping out of and/or being expelled from school). This issue could have an impact on their lower level of education. Coping with multiple and serious stressful life events from very early ages, especially when these take place in the family environment, is a risk factor for the chronification of social exclusion (Vázquez \& Panadero, 2016), as this situation appears to have a negative effect on the acquisition of skills that subsequently enable the establishment of stable relationships (Whitfield, 1998), and leads to adverse family histories that may limit the individual's ability to receive protective support 
in crisis situations (Herman et al., 1997). Furthermore, an accumulation of stressful life events in the early years of life increases the risk of psychoactive substance abuse and suffering from a wide variety of physical and mental health problems (Hatch \& Dohrenwend, 2007), and leads to a reduced quality of life (Krug, 2004) as well as affecting opportunities for maintaining stable housing or employment (Whitfield, 1998).

These circumstances may help to explain why the women living homeless in Madrid who had been mothers reported having consumed alcohol and drugs to a greater extent, mainly prior to becoming homeless, and having consumed both illegal psychoactive substances (heroin, cocaine, cannabis) and those available with a medical prescription (methadone, sedatives) to a greater extent. Among the differences in consumption, the higher levels of heroin consumption by the women who had been mothers is a particular concern, as this substance is enormously addictive, and habitual consumption leads to a marked physical and mental deterioration (Nyamathi, Longshore, Galaif, \& Leake, 2004). Not surprisingly, the consumption of psychoactive substances is one of the main reasons given by the women living homeless in Madrid to account for their loss of guardianship of their underage children.

In addition, the circumstances mentioned above may help explain why at the time of the interview, the homeless women who had been mothers were in a poorer state of health, which largely predated their homelessness, with high levels of serious illnesses or chronic diseases (including HIV/AIDS) and higher rates of disability. Furthermore, a very large majority of the women who were mothers had experienced unwanted pregnancies during their lives, as well as more miscarriages and abortions, mainly prior to becoming homeless. During the adult life of the interviewees who were mothers, a third had been sexually assaulted, more than half had suffered from physical violence, and $71 \%$ had suffered from intimate partner violence, and this took place for the first time prior to them becoming homeless in most cases. The large percentage of women victims of intimate partner violence who said they had a partner (more than half of those interviewed said they were not single) suggests that many of the mothers may have become homeless after leaving abusive partners. In addition, a relatively high percentage of women $(6 \%)$ had lost a child due to death, prior to becoming homeless in $80 \%$ of the cases. A particularly striking figure is that more than half of those interviewed who had been mothers said they had attempted suicide. This is a much higher percentage than the figure for people living homeless in Madrid (Panadero, Martín \& Vázquez, 2018) and for women living homeless (Vázquez \& Panadero, 2019). Most of the suicide attempts had occurred prior to the person concerned becoming homeless.

Engaging in disruptive behaviours from an early age, limited social support from the family, the need to survive in highly hostile circumstances and/or the excessive consumption of psychoactive substances may help account for the high level of criminal activity and the greater problems with the criminal justice system (arrests, detentions, convictions, imprisonment) observed among the women in a homeless situation who had been mothers. These problems occurred prior to them becoming homeless in around half of the cases, but at a mean age of around 30 years old, when they had had their first child in most cases. As Zlotnick et al. (2007) point out, it is understandable that most mothers in a homeless situation with histories of incarceration lived without their children, since in Spain imprisonment means having to resort to a caregiver or a foster home to care for children over three years of age.

At the time of the interview, the women who had been mothers consumed psychoactive substances more often and spent the night on the street more frequently than those who had not had children. These circumstances make them particularly vulnerable (Nyamathi et al., 2000). The higher levels of consumption of psychoactive substances, 
together with disruptive behaviours that could lead to them being temporarily expelled from the shelters, would account for their greater tendency to sleep on the street, and lead to the person concerned experiencing more stressful situations and greater physical and mental deterioration.

The limitations of this study include the fact that the criteria for sample inclusion in the research were restrictive (assignment to ETHOS operational categories 1,2 and 3), and there was no randomised or stratified selection of the women interviewed. Accordingly, it is impossible to guarantee the representativeness of the sample, despite the fact that the women interviewed account for a significantly large percentage of the total number of women living homeless in Madrid (Madrid City Council, 2018). It should also be noted that the study is limited to Madrid, Spain, which means that it is difficult to generalise its results to other contexts. Furthermore, this is a cross-sectional study design, and caution must therefore be exercised when trying to establish causal relationships.

Despite the limitations of the study, this research can help increase the visibility of the circumstances surrounding motherhood among women living homeless in Madrid, provide relevant information for designing and implementing public policies, facilities and care resources aimed at improving the situation of women living homeless and their children. In Madrid, the women living homeless who had been mothers presented particularly serious circumstances, which require the implementation of prevention and treatment programmes aimed specifically at this subgroup. These women presented extremely difficult life experiences, having suffered traumatic situations from an early age, with disruptive behaviours and substance abuse, which could have made their relationship and life with both their family of origin and their children much more difficult. The implementation of programmes aimed at providing specialised psychological help for these women, and facilitating their access to programmes for treatment of the consumption of psychoactive substances and promoting medical follow-ups that improve their health is therefore important. Furthermore, when circumstances permit, it would be useful to implement resources that enable them to meet their children and rebuild their relationship with them, and attempt to encourage facilitate their family reunification in cases where this is possible. It would be very important to facilitate access to protected housing for mothers with children living homeless, given that access to housing is a very important step towards the subsequent recovery of contact with their family.

Finally, future research aimed at examining various understudied circumstances affecting mothers in a homeless situation should be undertaken in more depth, including an analysis of the needs for support and healthcare advice in pregnancy, during the perinatal period, or after the decision to voluntarily terminate the pregnancy, if appropriate; analysis of their needs in terms of legal support in cases where they are separated from their children as a result of legal proceedings; and designing interventions aimed at restoring contact and establishing appropriate relationships with their children and their legal guardians when this separation has already taken place.

\section{Acknowledgments}

This work was supported by the "Agencia Estatal de Investigación" of the "Ministerio de Economía, Industria y Competitividad” of Spain under Grant FEM2016-75317-R. 


\section{References}

Anderson, L., Stuttaford, M., \& Vostanis, P. (2006). A family support service for homeless children and parents: User and staff perspectives. Child \& Family Social Work, 11(2), 119-127. Doi: doi.org/10.1111/j.1365-2206.2006.00399.x.

Anthony, E. R., Vincent, A., \& Shin, Y. (2018). Parenting and child experiences in shelter: A qualitative study exploring the effect of homelessness on the parent-child relationship. Child \& Family Social Work, 23(1), 8-15. Doi: doi.org/10.1111/cfs.12376.

Ayuntamiento de Madrid [Madrid City Council] (2019). Red de centros de atención a personas sin hogar [Care centers network for homeless people]. Madrid: Ayto. de Madrid. Retrieved from https:/www.madrid.es/portales/munimadrid/es/Inicio/ElAyuntamiento/Samur-Social-Personas-sin-hogar/Personas-sin-hogar/Red-deCentros/?vgnextfmt $=$ default\&vgnextchannel=920f9b6bf78b8310VgnVCM2000000c205a 0aRCRD\&vgnextoid=920f9b6bf78b8310VgnVCM2000000c205a0aRCRD

Ayuntamiento de Madrid [Madrid City Council] (2018). Informe IX Recuento de Personas sin hogar en Madrid [Report IX Homeless People Count in Madrid]. Madrid: Ayto. de Madrid. Retrieved from https://www.madrid.es/UnidadesDescentralizadas/IntegracionyEmergenciaSocial/SAMU R\%20Social/ficheros/INFORME\%20RECUENTO\%202018_FINAL.pdf

Baptista, I., Benjaminsen, L., Pleace, N., \& Busch-Geertsema, V. (2017). Family Homelessness in Europe: 7 EOH Comparative Studies in Homeless. Brussels: Brussels: FEANTSA.

Barrow, S. M., \& Laborde, N. D. (2008). Invisible mothers: Parenting by homeless women separated from their children. Gender Issues, 25(3), 157-172. Doi: 10.1007/s12147-0089058-4.

Bassuk, E.L., Buckner, J.C., Perloff, J.N., \& Bassuk, S.S. (1998). Prevalence of mental health and substance use disorders among homeless and low-income housed mothers. American Journal of Psychiatry, 155(11), 1561-1564. Doi: 10.1176/ajp.155.11.1561.

Belcher, J. R., Greene, J. A., McAlpine, C., \& Ball, K. (2001). Considering pathways into homelessness: Mothers, addictions, and trauma. Journal of Addictions Nursing, 13(3-4), 199-208. Doi: 10.3109/10884600109052654.

Burt, M. R., Aron, L. Y., \& Lee, E. (2001). Helping America's homeless: Emergency shelter or affordable housing? Washington D.C.: The Urban Insitute Press.

Chambers, C., Chiu, S., Scott, A.N., Tolomiczenko, G., Redelmeier, D.A., Levinson, W., \& Hwang, S.W. (2014). Factors associated with poor mental health status among homeless women with and without dependent children. Community Mental Health Journal, 50(5), 553-559. Doi: 10.1007/s10597-013-9605-7.

Corus, C., Saatcioglu, B., Kaufman-Scarborough, C., Blocker, C. P., Upadhyaya, S., \& Appau, S. (2016). Transforming poverty-related policy with intersectionality. Journal of Public Policy \& Marketing, 35(2), 211-222. Doi: doi.org/10.1509/jppm.15.141

Cowal, K., Shinn, M., Weitzman, B. C., Stojanovic, D., \& Labay, L. (2002). Mother-child separations among homeless and housed families receiving public assistance in New York City. American Journal of Community Psychology, 30(5), 711-730. Doi: doi.org/10.1023/A:1016325332527

Glick, J. E. (1996). Mothers with children and mothers alone: Comparison of homeless families. The Journal of Sociology \& Social Welfare, 23(6), 85-94.

Guillén, A., Marín-Martín, C., Panadero, S., \& Vázquez, J.J. (in press). Substance use, stressful life events and mental health: A longitudinal study among homeless women in Madrid (Spain). Addictive Behaviors. DOI: 10.1016/j.addbeh.2019.106246. 
Grant, R., Gracy, D., Goldsmith, G., Shapiro, A., \& Redlener, I. E. (2013). Twenty-five years of child and family homelessness: Where are we now? American Journal of Public Health, 103, E1-E10. Doi: 10.2105/AJPH.2013.301618

Hanrahan, P., McCoy, M. L., Cloninger, L., Dincin, J., Zeitz, M. A., Simpatico, T. A., \& Luchins, D. J. (2005). The mother's project for homeless mothers with mental illnesses and their children: A pilot study. Psychiatric Rehabilitation Journal, 28(3), 291-294. Doi: dx.doi.org/10.2975/28.2005.291.294.

Haskett, M. E., Loehman, J., \& Burkhart, K. (2016). Parenting interventions in shelter settings: A qualitative systematic review of the literature. Child \& Family Social Work, 21(3), 272-282. Doi: doi.org/10.1111/cfs.12147

Hatch, S.L. \& Dohrenwend, B.P. (2007). Distribution of traumatic and other stressful life events by race/ethnicity, gender, SES, and age: A review of the research. American Journal of Community Psychology, 40, 313-332. DOI: 10.1007/s10464-007-9134-z

Herman, D.B., Susser, E.S., Struening, E.L., \& Link, B.L. (1997). Adverse childhood experiences: Are they risk factors for adult homelessness? American Journal of Public Health, 87(2), 249-255. DOI: 10.2105/AJPH.87.2.249.

Krug, E.G. (2004). Injury surveillance is key to preventing injuries. Lancet, 364, 1563-1566. DOI: dx.doi.org/10.1016/S0140-6736(04)17328-5.

Leonori, L., Muñoz, M., Vázquez, C., Vázquez, J.J., Bravo, M., Nuche, M., Brandt, P., Bento A. \& Horenbek, B. (2000). The mental health and social exclusion European network: A research activity report on European homeless citizens. European Psychologist, 5(3), 245-251. Doi: 10.1027//1016-9040.5.3.245.

Muñoz, M., Vázquez, C., \& Vázquez, J.J. (2004) A comparison between homeless, domiciled and vulnerable populations in Madrid. Population, 59 (1), 129-141. Doi: $10.2307 / 3654931$.

Murrell, N. L., Scherzer, T., Ryan, M., Frappier, N., Abrams, A., \& Roberts, C. (2000). The AfterCare Project: An intervention for homeless childbearing families. Family \& Community Health, 23(3), 17-27.

New York City Commission on the Homelessness. (1992). The way home: A new direction in social policy. New York: Author.

Nyamathi, A., Leake, B., \& Gelberg, L. (2000). Sheltered versus nonsheltered homeless women. Journal of General Internal Medicine, 15(8), 565-572. Doi: doi.org/10.1046/j.1525-1497.2000.07007.x

Nyamathi, A., Longshore, D., Galaif, E. R., \& Leake, B. (2004). Motivation to stop substance use and psychological and environmental characteristics of homeless women. Addictive Behaviors, 29(9), 1839-1843. Doi: doi.org/10.1016/j.addbeh.2004.03.032.

Panadero, S., Guillén, A.I. \& Vázquez, J.J. (2015). Happiness on the street. Overall happiness among homeless people in Madrid (Spain). American Journal of Orthopsychiatry, 85(4), 324-330. Doi: dx.doi.org/10.1037/ort0000080.

Panadero, S., Martín, R.M., \& Vázquez, J.J. (2018). Suicide attempts and stressful life events among homeless people in Madrid (Spain). Journal of Community and Applied Social Psychology, 28(4), 200-212. Doi: 10.1002/casp.2351.

Pavao, P., Alvarez, J., Baumrind, N., Induni, M., \& Kimerling, R. (2007). Intimate partner violence and housing instability. American Journal of Preventive Medicine, 32, $143-$ 146. Doi: doi.org/10.1016/j.amepre.2006.10.008.

Roll, Carolyn N., Toro, Paul A. \& Ortola, Gina L. (1999). Characteristics and experiences of homeless adults: A comparison of single men, single women, and women with children. Journal of Community Psychology, 27(2), 189-198. Doi: AID-JCOP6>3.0.CO;2-M. 
Rossi, P. H. (1994). Troubling families: Family homelessness in America. American Behavioral Scientist, 37(3). 342-395. Doi: doi.org/10.1177/0002764294037003003.

Shinn, M., \& Weitzman, B. (1996). Homeless families are different. In Homelessness in America: A reference book. National Coalition for the Homeless and Oryx Press.

Spanish National Institute of Statistics (2018, May 15). Edad media de maternidad por provincia, según orden de nacimiento [Average age of motherhood by province, according to birth order]. Retrieved from http://www.ine.es/jaxiT3/Tabla.htm?t=1581\&L=0

Tucker, J. S., Kennedy, D., Ryan, G., Wenzel, S. L., Golinelli, D., \& Zazzali, J. (2009). Homeless women's personal networks: Implications for understanding risk behavior. Human organization, 68(2), $129 . \quad$ Doi: dx.doi.org/10.17730/humo.68.2.m23375u1kn033518

Vázquez, J.J., Berrios, A., Bonilla, E., \& Suarez, A. (2019). Homeless people in León (Nicaragua): Conceptualizing and measuring homelessness in a developing country. American Journal of Orthopsychiatry, 89(2), 296-303. Doi: dx.doi.org/10.1037/ort0000336.

Vázquez, J.J. \& Panadero, S. (2016). Chronicity and pseudo inheritance of social exclusion: Differences according to the poverty of the family of origin among trash pickers in León (Nicaragua). Human Rights Quarterly, 38(2), 379-390. Doi: 10.1353/hrq.2016.0037.

Vázquez, J.J. \& Panadero, S. (2019). Suicidal attempts and stressful life events among women in a homeless situation in Madrid (Spain). American Journal of Orthopsychiatry, 89(2), 304-311. Doi: dx.doi.org/10.1037/ort0000387.

Vázquez, J.J., Panadero, S., Martín, R.M. \& Díaz-Pescador, V. (2015). Access to new information and communication technologies among homeless people in Madrid (Spain). Journal of Community Psychology, 43(3), 338-347. Doi: 10.1002/jcop.21682.

Vázquez, J.J., Panadero, S. \& Pascual, I. (in press). The particularly vulnerable situation of women living homeless in Madrid (Spain). Spanish Journal of Psychology.

Vázquez, J.J., Panadero, S. \& Zúñiga, C. (2017a). Content and uniformity of stereotypes and meta-stereotypes of homeless people in Madrid (Spain). Journal of Community Psychology, 45(1), 128-137. Doi: 10.1002/jcop.21836.

Vázquez, J.J., Panadero, S. \& Zúñiga, C. (2017b). Actors, observers, and causal attributions of homelessness: Differences in attribution for the causes of homelessness among domiciled and homeless people in Madrid. American Journal of Orthopsychiatry, 87(1), 15-22. Doi: dx.doi.org/10.1037/ort0000130.

Vázquez, J.J., Panadero, S. \& Zúñiga, C. (2018). Attributions about homelessness in homeless and domiciled people in Madrid, Spain: «Why are they homeless people?». American Journal of Orthopsychiatry, 88(2), 236-247. Doi:dx.doi.org/10.1037/ort000024.

Weinreb, L. F., Buckner, J. C., Williams, V., \& Nicholson, J. (2006). A Comparison of the health and mental status of homeless mothers in Worcester, Mass: 1993 and 2003. American Journal of Public Health, 96(8), 1444-1448. Doi: 10.2105/AJPH.2005.069310.

Whitfield, C. L. (1998). Adverse childhood experiences and trauma. American Journal of Preventive Medicine, 14(4), 361-364. Doi:10.1016/S0749-3797(98)00013-0.

Zabkiewicz, D.M., Patterson, M. \& Wright, A. (2014). A cross-sectional examination of the mental health of homeless mothers: Does the relationship between mothering and mental health vary by duration of homelessness? BMJ OPEN, 4(12), 1-8. Doi:10.1136/bmjopen2014-006174.

Zlotnick, C., Kronstadt, D., \& Klee, L. (1998). Foster care children and family homelessness. American Journal of Public Health, 88(9), 1368-1370. Doi: 10.2105/AJPH.88.9.1368. 
Zlotnick, C., Robertson, M. J., \& Lahiff, M. (1999). Getting off the streets: Economic resources and residential exits from homelessness. Journal of Community Psychology, 27(2), 209-224. Doi: doi.org/10.1002/(SICI)1520-6629(199903)27:2<209::AIDJCOP8 $>3.0 . \mathrm{CO} ; 2-2$.

Zlotnick, C., Tam, T. \& Bradley, K. (2007). Impact of adulthood trauma on homeless mothers. Community Mental Health Journal, 43(1), 13-32. Doi: 10.1007/s10597-0069070-7.

Zlotnick, C., Tam, T., \& Robertson, M. J. (2004). Adverse childhood events, substance abuse, and measures of affiliation. Addictive Behaviors, 29(6), 1177-1181. Doi: doi.org/10.1016/j.addbeh.2004.01.005.

Zugazaga, C. (2004). Stressful life event experiences of homeless adults: A comparison of single men, single women, and women with children. Journal of Community Psychology, 32(6), 643-654. Doi:10.1002/jcop.20025. 